7. Reprod. Fert. (1967) 13, 365-367

BRIEF COMMUNICATION

\title{
THE IMPORTANCE OF CAPACITATION FOR ESTABLISHING CONTACT BETWEEN EGGS AND SPERM IN THE RABBIT
}

\author{
J. M. BEDFORD* \\ Department of Physiology, The Royal Veterinary College, London
}

(Received 11th November 1966)

The first barrier presented to rabbit spermatozoa at the site of fertilization is the cell mass which comprises the cumulus oophorus and, immediately surrounding the ovum, the corona radiata. Fertilization in the mouse, rat and rabbit occurs before dispersion of these granulosa cells (Lewis \& Wright, 1935; Austin, 1948a, b; Chang, 195la). In studies of the interaction of spermatozoa with the cumulus of the rat, rabbit and hamster in vitro, Austin (1960) observed that epididymal or ejaculate spermatozoa were apparently unable to penetrate the cumulus oophorus, whereas under similar conditions spermatozoa were seen moving freely through the cumuli obtained from mated animals. This observation led Austin to suggest that capacitation, which occurs while the spermatozoa are in the female tract (Austin, 1951; Chang, 1951b), may facilitate sperm passage through the cumulus oophorus to the surface of the zona pellucida. This suggestion has been tested in the rabbit, in vivo, in the manner described below.

Spermatozoa flushed from rabbit uteri with Hanks' solution 12 to $14 \mathrm{hr}$ after natural mating were concentrated by centrifugation at $1000 \mathrm{rev} / \mathrm{min}$ for $5 \mathrm{~min}$. Aliquots of $0.03 \mathrm{ml}$ containing $100 \pm 15 \cdot 7 \times 10^{3}$ motile spermatozoa were then inseminated via the fimbria into the tubal ampulla on one side of female rabbits, $11 \frac{1}{2} \mathrm{hr}$ after administration of an ovulation injection (Pregnyl: Organon). A similar volume containing $360 \pm 16.0 \times 10^{3}$ spermatozoa taken directly from the vas deferens and cauda epididymidis was inseminated likewise into the contralateral Fallopian tube. The ova were flushed from the oviduct 5 to $6 \mathrm{hr}$ later (17 to $18 \mathrm{hr}$ after injecting Pregnyl), at which time all or most of the corona cells had fallen away from the surface of the zona pellucida. The ova were mounted and fixed for $1 \mathrm{hr}$ in acetic alcohol, stained lightly with $1 \%$ lacmoid, and, using positive phase optics, were examined for fertilization and more particularly for the number of spermatozoa attached to each ovum. The spermatozoa adhering to the eggs were counted accurately by focusing through the depth of the ovum from one surface to the other. A proportion of the

\footnotetext{
* Present address: The Worcester Foundation for Experimental Biology, 222 Maple Avenue, Shrewsbury, Massachusetts, U.S.A.
} 
spermatozoa in association with ova exposed to capacitated spermatozoa were situated in the perivitelline space, but the majority counted were on or within the zona pellucida (Plate 1).

From Table 1, it is obvious that the number of spermatozoa in association with ova exposed to capacitated sperm samples was significantly greater $(P<0.01)$ than the very small number adhering to ova exposed for the same length of time to a higher concentration of mature epididymal spermatozoa. In the latter group, the complete absence of spermatozoa on most ova, and the very low numbers on the remainder, could not have been due to loss of spermatozoa from the fertilization site; for, when comparable numbers of epididymal spermatozoa were inseminated into the tubes of females 9 to $11 \mathrm{hr}$ before ovulation, many spermatozoa were found consistently on the surface of ova collected about $7 \mathrm{hr}$ after ovulation (Table 1).

TABLE 1

THE INFLUENCE OF CAPACITATION ON SPERM/OVUM CONTACT

\begin{tabular}{|c|c|c|c|c|c|c|c|}
\hline Sperm sample & $\begin{array}{c}\text { Mean No. of } \\
\text { sperm. } \times 10^{3} \\
\text { tubbe }\end{array}$ & $\begin{array}{c}\text { Time of } \\
\text { insemination* } \\
\text { before }(-) \text { or } \\
\text { after (+) } \\
\text { ovulation } \\
(h r)\end{array}$ & $\begin{array}{c}\text { No. } \\
\text { expts. }\end{array}$ & $\begin{array}{l}\text { No. } \\
\text { ơ }\end{array}$ & $\begin{array}{c}\text { Ova } \\
\text { recovered }\end{array}$ & $\begin{array}{c}\% \text { Ova } \\
\text { fertilized }\end{array}$ & $\begin{array}{c}\text { Mean No. } \\
\text { sperm/ovim } \\
\text { (range) }\end{array}$ \\
\hline $\begin{array}{l}\text { A. Uterine } \\
\text { (capacitated) }\end{array}$ & $100 \pm 15 \cdot 7 * \dagger$ & +1 to 1.5 & ל 11 & 17 & 66 & 78 & $\begin{array}{c}31 \cdot 6 \pm 5 \cdot 7 * \dagger \\
(1 \text { to } 140)\end{array}$ \\
\hline B.Epididymal & $360 \pm 16 \cdot 0$ & +1 to 1.5 & & & 83 & 0 & $\begin{array}{c}1.9 \pm 0.22 \\
(0 \text { to } 6)\end{array}$ \\
\hline C.Epididymal & $460 \pm 19 \cdot 8$ & -9 to 11 & 36 & 36 & 254 & 96 & $\begin{array}{c}103.4 \pm 24.2 \\
(14 \text { to } 250)\end{array}$ \\
\hline
\end{tabular}

* Ova exposed to spermatozoa for 5 to $7 \mathrm{hr}$.

† S.E.

The present experiments indicate that, in the rabbit, capacitation not only invests spermatozoa with the competence to penetrate the ovum, but also endows them with the ability to establish contact with the surface of the zona pellucida during the fertile life of the ovum ( 6 to $8 \mathrm{hr}$ after ovulation: Chang, 1952; Adams \& Chang, 1962b). In previous studies involving tubal insemination of non-capacitated spermatozoa at or soon after the time of ovulation, it was noted that these spermatozoa had attached to but had not penetrated unfertilized ova (Chang, 1955; Noyes, Walton \& Adams, 1958). Ova were usually recovered in the latter experiments, not earlier than about $24 \mathrm{hr}$ after ovulation; hence the spermatozoa found lying on the zona surface would have had ample time before collection of the ova to have become capacitated in the Fallopian tube (in $10 \mathrm{hr}$ : Adams \& Chang, 1962a), though too late for fertilization.

It is not certain at which level capacitation acts to facilitate the establishment of sperm/egg contact. Clearly this could operate at the level of the surrounding cell barrier, as well as at the point of adhesion between the spermatozoa and the zona surface. The observations of Austin (1960) make it seem likely that the advantage conferred by capacitation does involve the ability of spermatozoa to 
PLATE 1

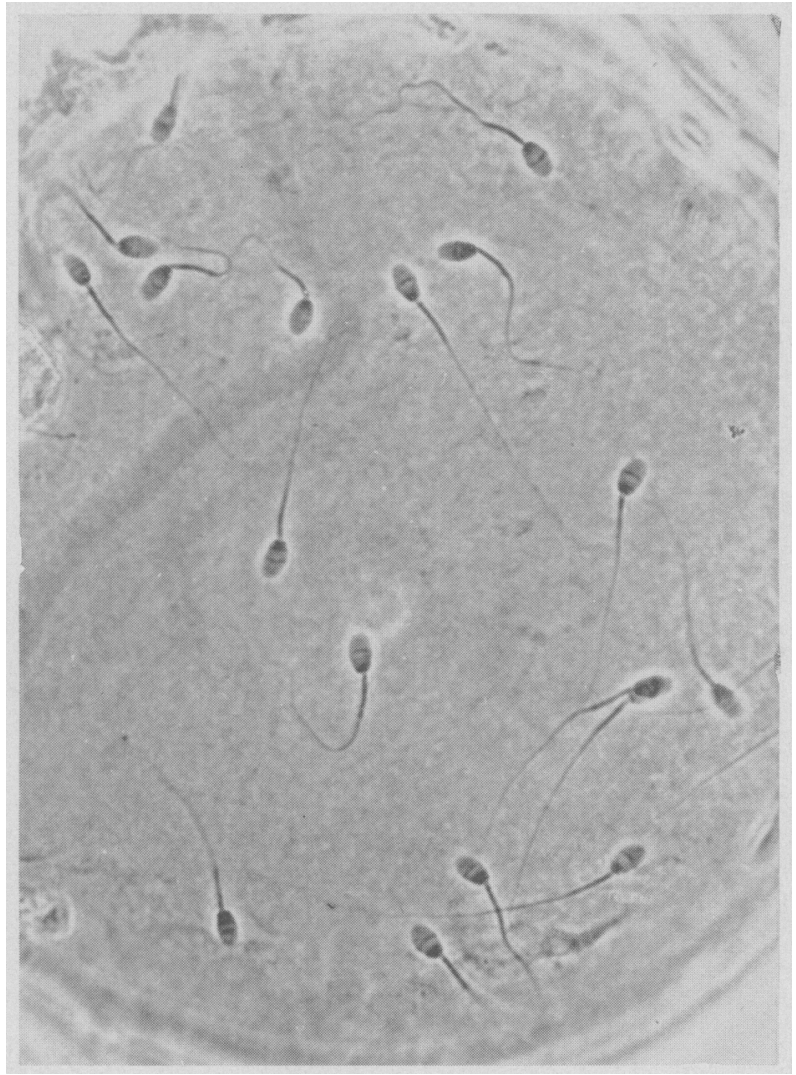

Spermatozoa on the zona surface of a rabbit ovum recovered $6 \mathrm{hr}$ after tubal insemination of capacitated spermatozoa. Lacmoid, $\times 550$.

(Facing p. 366) 
penetrate the cells surrounding the fresh ovum, though it is still not sure whether hyaluronidase is an important factor at this stage. Washed ejaculate or mature epididymal spermatozoa will stick readily to the surface of the zona pellucida in vitro. In view of the fact, however, that many ova in the present study would have been denuded 1 to $2 \mathrm{hr}$ before their collection (Chang, 1952; Dickmann, 1963), the virtual absence of epididymal spermatozoa on the surface of the ova in group B suggests that, in vivo, capacitation might possibly also influence the ability of the spermatozoa to adhere to the surface of the ovum.

\section{REFERENCES}

Adams, G. E. \& Chang, M. C. (1962a) Capacitation of rabbit spermatozoa in the Fallopian tube and in the uterus. F. exp. Zool. 151, 159.

Adams, C. E. \& Chang, M. E. (1962b) The effect of delayed mating on fertilization in the rabbit. $\mathcal{F}$. exp. Zool. 151, 155.

Austin, C. R. (1948a) Function of hyaluronidase in fertilization. Nature, Lond. 162, 63.

Austrs, C. R. (1948b) Number of sperms required for fertilization. Nature, Lond. 162, 534.

Austin, C. R. (1951) Observations on the penetration of the sperm into the mammalian egg. Aust. 7 . scient. Res. B, 4, 581 .

Austin, C. R. (1960) Capacitation and release of hyaluronidase. F. Reprod. Fert. 1, 310.

Chang, M. C. (1951a) Fertility and sterility as revealed in the study of fertilization and development of rabbit eggs. Fert. Steril. 2, 205.

Chang, M. C. (1951b) The fertilizing capacity of spermatozoa deposited into the Fallopian tubes. Nature, Lond. 168, 697.

Chang, M. C. (1952) Fertilizability of rabbit ova and the effects of temperature in vitro on their subsequent fertilization and activation in vivo. F. exp. Zool. 121, 351.

Chang, M. G. (1955) Development of fertilizing capacity of rabbit spermatozoa in the uterus. Nature, Lond. 175, 1036.

Dickmann, Z. (1963) Denudation of the rabbit egg: time sequence and mechanism. Am. J. Anat. 113, 303.

LEWIs, W. H. \& WRIGHT, E. S. (1935) On the early development of the mouse egg. Contr. Embryol. 25, 113.

Noyes, R. W., Walton, A. \& Adams, C. E. (1958) Capacitation of rabbit spermatozoa. F. Endocr. 17, 374. 